\title{
Studi Penggunaan Antibiotik Berdasarkan ATC/DDD Pada Pasien Bedah Orthopedi Di RSUD Abdul Wahab Sjahranie Samarinda
}

\author{
Fitriyani*, Adam M. Ramadhan, Febrina Mahmudah \\ Laboratorium Penelitian dan Pengembangan Kefarmasian "Farmaka Tropis", \\ Fakultas Farmasi, Universitas Mulawarman, Samarinda, Indonesia \\ *Email: Fitryyani131@gmail.com
}

\begin{abstract}
Fracture is a breakdown of bone continuity, in the treatment can be done conservatively or surgically. In the surgical process not a few microbes that enter or accidentally enter into the limbs are in surgery so that antibiotics need to be used. This study aims to determine the patient characteristics and quantity of antibiotic use in orthopedic surgery patients. This study was an observational study with retrospective data collection. Data on antibiotic use were analyzed descriptively by the ATC / DDD method and DU $90 \%$ of medical record records, with inclusion criteria for orthopedic, adult, and hospitalized surgical patients at Abdul Wahab Sjahranie Hospital in Samarinda during the period of January-December 2017. Characteristic results were obtained, the majority of male sexes were 54 patients (63.52\%), age 46-65 years were 35 patients $(41.18 \%)$, and the type of private work was 34 patients (40\%). The use of antibiotics based on ATC/DDD was obtained at 20.21 DDD/100 patient-days in the ceftriaxone and antibiotic drug categories included in the DU 90\% segment were ceftriaxone, cefixime, cefadroxil, and amoxicillin.
\end{abstract}

Keywords: ATC / DDD, Antibiotics, Orthopedic Surgery, Du 90\%

\begin{abstract}
ABSTRAK
Fraktur adalah terputusnya kontinuitas tulang, pada penanganannya dapat dilakukan teknik konservatif atau dengan pembedahan. Pada proses pembedahan tidak sedikit mikroba yang ikut masuk atau tidak sengaja masuk kedalam anggota tubuh yang di bedah sehingga perlu digunakan antibiotik. Penelitian ini bertujuan untuk mengetahui karakteristik pasien dan kuantitas penggunaan antibiotik pada pasien bedah orthopedi. Penelitian ini adalah penelitian observasional dengan pengambilan data secara retrospektif. Data penggunaan antibiotik dianalisis secara deskriptif dengan metode ATC/DDD dan DU 90\% dari catatan rekam medik, dengan kriteria inklusi pasien bedah orthopedi, dewasa, dan rawat inap di Rumah Sakit Abdul Wahab Sjahranie Samarinda selama periode Januari-Desember 2017. Hasil penelitian karakteristik diperoleh terbanyak jenis kelamin laki-laki sebesar 54 pasien (63,52\%), usia 46-65 tahun sebesar 35 pasien $(41,18 \%)$, dan jenis pekerjaan swasta sebesar 34 pasien (40\%). Penggunaan antibiotik berdasarkan ATC/DDD diperoleh sebesar 20,21 DDD/100 patient-days pada kategori obat ceftriaxone dan antibiotik yang masuk dalam segmen DU 90\% adalah ceftriaxone, cefixime, cefadroxil, dan amoxicillin.
\end{abstract}


Kata kunci : ATC/DDD, Antibiotik, Bedah orthopedi, Du 90\%

DOI: $\underline{\text { https://doi.org/10.25026/mpc.v8i1.325 }}$

\section{PENDAHULUAN}

Menurut Global Status Report On

Road Safety, lebih dari 1,2 juta korban meninggal setiap tahun di dunia dan antara 20 sampai 50 juta menderita luka akibat kecelakaan lalu lintas. Berdasarkan Riskesdas terdapat kecendrungan peningkatan cedera dari $7,5 \%$ pada tahun 2007 menjadi 8,2\% pada tahun 2013. Penyebab cedera terbanyak yang kedua adalah kecelakaan sepeda motor (40,6\%). Proporsi jenis cedera patah tulang berada diurutan ke tiga sebanyak $5,8 \%$ di Indonesia ${ }^{[6]}$. Kota Samarinda memiliki jumlah kecelakaan lalu lintas terbanyak di urutan ketiga pada tahun 2016 dengan jumlah kecelakaan sebesar 133 kejadian $^{[1]}$. Dampak yang mungkin terjadi pada kecelakaan yaitu terjadinya fraktur. Penanganan dari fraktur ini dapat dilakukan dengan teknik konservatif dan pembedahan. Dalam proses pembedahan tidak sedikit mikroba yang ikut masuk atau tidak sengaja masuk kedalam anggota tubuh yang di bedah sehingga perlu digunakan antibiotik. Pemilihan antibiotik harus berdasarkan indikasi yang tepat, karena penggunaan antibiotik yang tidak rasional dapat menyebabkan resistensi, reaksi alergi, toksisitas, dan perubahan fisiologi.

$$
\text { World Health Organization }
$$

(WHO) mengembangkan suatu sistem klasifikasi dan unit perhitungan dalam studi penggunaan obat yaitu sistem klasifikasi Anatomical Therapeutic Chemical (ATC) dan Unit Perhitungan Defined Daily Dose (DDD). Defined Daily Dose (DDD) adalah asumsi dosis rata-rata per hari. Penggunaan antibiotik untuk indikasi tertentu pada orang dewasa. Metode drug utilization 90\% (DU 90\%) adalah metode yang menunjukkan pengelompokkan obat yang sering digunakan bersama dengan metode ATC/DDD. Penilaian terhadap obat yang masuk kedalam segmen $90 \%$ ini diperlukan dalam hal evaluasi, pengendalian pengggunan dan perencanaannya.

\section{METODE}

Penelitian ini merupakan penelitian observasional, yaitu penelitian yang dilakukan dengan tujuan utama untuk mengetahui karaketeristik dan kuantitas penggunaan antibiotik pada pasien bedah orthopedi di RSUD Abdul Wahab Sjahranie Samarinda. Metode pengambilan sampel yang digunakan adalah metode purposive sampling. Penelitian dilakukan dengan menganalisa data rekam medik pasien, selanjutnya ditentukan karakteristik pasien dan menghitung kuantitas penggunaan antibiotik pada pasien bedah orthopedi di RSUD Abdul Wahab Sjahranie Samarinda pada periode JanuariDesember 2017.

Populasi pasien bedah orthopedi yang diperoleh sebanyak 85 pasien. Pengambilan data diperoleh dari data rekam medik pasien bedah orthopedi di RSUD abdul wahab sjahranie samarinda. Sampel yang dianalisis adalah pasien bedah orthopedi yang dirawat inap di RSUD Abdul Wahab Sjahranie Samarinda Periode Januar-Desember 2017.

Pengumpulan data dilakukan
dengan menganalisa aspek-aspek
kelengkapan data rekam medik pada
setiap pasien kemudian dicatat pada
lembar pengumpulan data. Data dianalisis
secara deskriptif disajikan dalam bentuk


persentase dan ditampilkan dalam bentuk diagram.

\section{HASIL DAN PEMBAHASAN}

\section{Karakteristik Pasien}

Hasil karakteristik jenis kelamin dapat dilihat pada Gambar 1.Berdasarkan tabel tersebut dapat diperoleh terbanyak jenis kelamin laki-laki sebesar 54 pasien $(63,52 \%)$. Berdasarkan hasil karakteristik jenis kelamin diperoleh gambaran bahwa pasien fraktur banyak dialami oleh pasien laki-laki. Karena laki-laki lebih sering melakukan aktivitas di luar. Disamping itu, diperkirakan bahwa laki-laki lebih banyak terpapar terhadap resiko cedera dilingkungan pekerjaannya.

Distribusi berdasarkan karakteristik usia yang terbanyak yaitu pada usia 46-65 tahun sebesar 35 pasien
$(41,18 \%)$, hal ini sesuai dengan penelitian yang dilakukan oleh Mariana, ditemukan bahwa kelompok usia lebih dari 45 tahun lebih berisiko mendapat status cedera dibanding dengan kelompok usia kurang dari 45 tahun $^{[8]}$. Tingkat keparahan cedera yang tinggi pada usia ini dipengaruhi oleh komplikasi penyakit yang umum diderita orang tua, perubahan fisiologi tubuh seiring pertambahan usia, dorongan untuk kembali mengendarai motor pada usia ini cukup tinggi sementara kemampuan dalam mengendarai sepeda motor berkurang dibanding saat muda dahulu. Kejadian cedera parah lebih tinggi terjadi pada penduduk usia 60 tahun keatas di Hunan Cina, hal ini terkait dengan kondisi fisiologis yang sudah menurun, persepsi keselamatan dan reaksi yang lambat terhadap situasi yang berbahaya ${ }^{[2]}$.

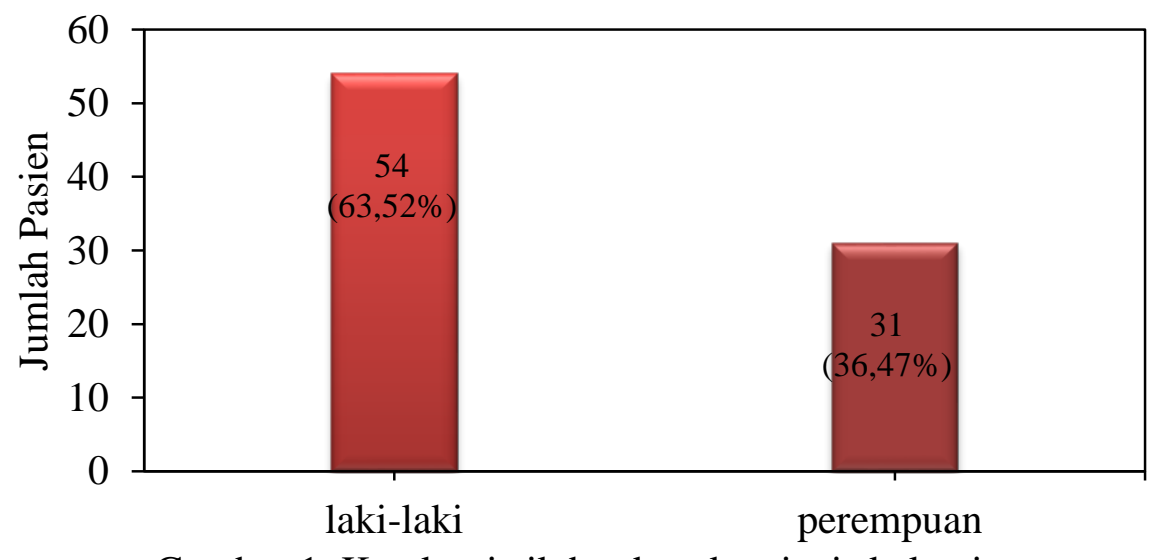

Gambar 1. Karakteristik berdasarkan jenis kelamin

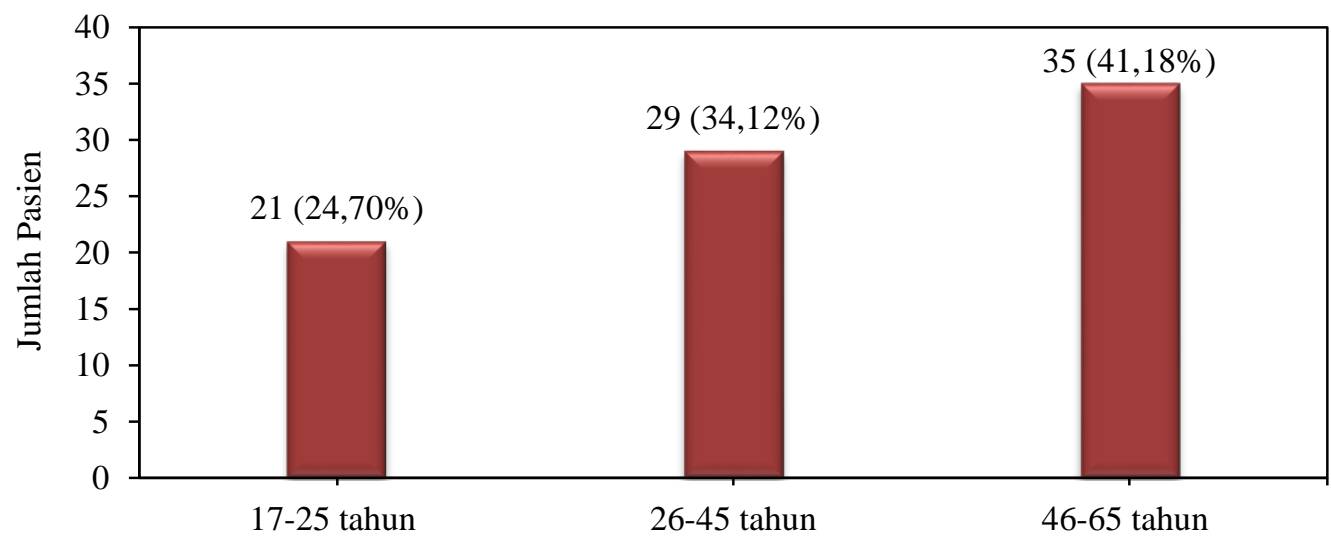

Gambar 2. Karakteristik berdasarkan usia 


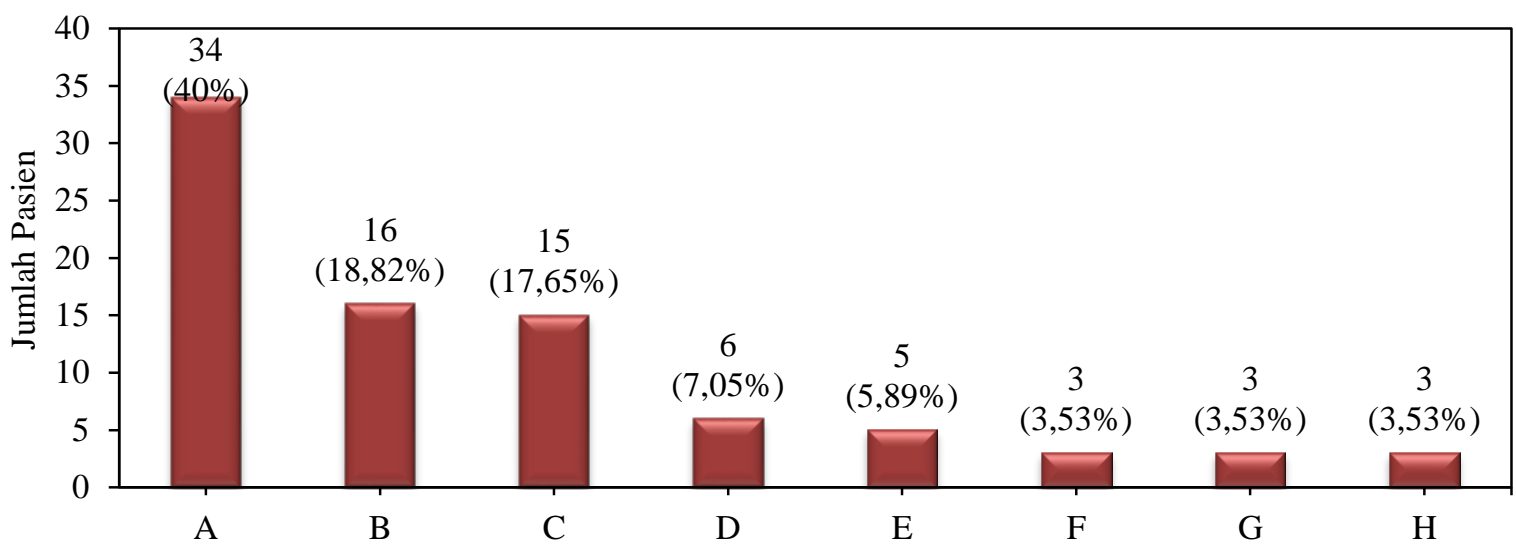

Gambar 3. Karakteristik Berdasarkan Jenis Pekerjaan (A) Swasta, (B)Tidak Ada Status, (C) Tidak Bekerja, (D) Belum Bekerja, (E)Petani, (F) Wiraswasta, (G) PNS, (H) Pegawai Pemerintah Non PNS

Karakteristik berdasarkan jenis pekerjaan terbanyak yaitu pekerjaan swasta, dimana pada tempat terjadinya cedera pada penelitian ini berpola pada jenis pekerjaan yaitu lebih banyak terjadi dijalan raya. Hal ini sesuai dengan penyebab terjadinya terbanyak adalah kejadian kecelakaan lalulintas. Pada petani dan buruh, cedera lebih tinggi terjadi diindustri, konstruksi ataupun pertanian dibandingan pekerjaan pegawai. Pada hasil penelitian ini menerangkan pada petani dan buruh (swasta), karena area kerjanya beresiko menimbulkan cedera. Hal ini sesuai dengan analisis oleh Suwandra, bahwa pekerjaan seseorang dapat mencerminkan status sosial, pendidikan, resiko cedera, dan masalah kesehatan. Dalam hal jenis pekerjaan, pekerjaan swasta juga berpengaruh terhadap resiko cedera korban kecelakaan $^{[11]}$.

\section{Kuantitas Antibiotik Berdasarkan DDD/100 patient-days}

Berdasarkan 85 catatan rekam medik pasien bedah orthopedi pada tahun 2017 yang diambil, terdapat 244 peresepan antibiotik. Berdasarkan peresepan tersebut diperoleh data kuantitas yang menunjukkan bahwa obat antibiotik ceftriaxone adalah yang paling banyak digunakan dibandingkwan penggunaan antibiotik lain yang ditampilkan pada tabel 1 .

Analisis kuantitas penggunaan antibiotik dilakukan dengan menghitung DDD (Defined Daily Dose). DDD diasumsikan sebagai dosis rata-rata pemeliharaan perhari untuk obat yang digunakan orang dewasa dalam penelitian ini didapatkan 7 jenis antibiotik yang digunakan dalam penanganan bedah orthopedi di RSUD Abdul Wahab Sjahranie Samarinda dengan total 26,22 DDD/100 patient-days. Data kuantitas penggunaan antibiotik dapat dilihat pada tabel 4, dari data tersebut semakin besar nilai DDD/100 patient-days, maka semakin besar juga penggunaan antibiotik. Hal ini dapat dilihat bahwa penggunaan ceftriaxone pada tahun 2017 adalah yang terbanyak yaitu sebesar 20,21 DDD/100 patient-days, yang artinya dari 100 pasien rawat inap setiap harinya ada sekitar 20 pasien yang mendapatkan $2000 \quad \mathrm{mg}$ antibiotik ceftriaxone. Hal ini sama dengan penelitian oleh Permatasari yang mendapatkan peresepan antibiotik terbesar berasal dari golongan sefalosporin generasi ke tiga yaitu ceftriaxone sebesar 61,63 DDD/100 patient-days $^{[10]}$. Berdasarkan penelitian yang dilakukan oleh Hamdi, konsumsi antibiotik terbanyak yaitu golongan sefalosporin sebanyak 35,8 DDD/100 
hari rawat. Dari golongan sefalosporin yang digunakan, $21 \%$ adalah generasi ke3 , generasi pertama sebanyak $20,8 \%$ dan $15,2 \%$ generasi kedua ${ }^{[5]}$. Begitu juga pada penelitian oleh Fazriyah, penggunaan antibiotik tertinggi pada pasien apendektomi adalah ceftriaxone mencapai 46,52 DDD/100 patient-days ${ }^{[3]}$.

Hasil pada penelitian ini, antibiotik ceftriaxone adalah obat yang paling sering digunakan khususnya pada bedah orthopedi sebagai antibiotik profilaksis, hal ini sama dengan penelitian Kigera menemukan bahwa ceftriaxone generasi ketiga sefalosporin adalah satu-satunya obat yang digunakan dalam profilaksis bedah. Meskipun sefalosporin generasi pertama adalah antibiotik yang direkomendasikan untuk profilaksis bedah diorthopedi, penggunaan paling banyak ceftriaxone dalam penelitian ini mungkin karena spektrum antibakteri yang luas dan biaya ceftriaxone generik yang lebih murah di pasar lokal ${ }^{[7]}$. Ceftriaxone dan cefotaxime juga telah digunakan sebagai antibiotik profilaksis di beberapa rumah sakit seluruh dunia. Administrasi ceftriaxone sebagai antibiotik profilaksis telah terbukti lebih efektif untuk mengurangi kejadian SSI (Site Surgical Infections), dimana dosis tunggal ceftriaxone secara signifikan mengurangi risiko SSI (Site Surgical Infections) dan penggunaannya telah terbukti menghemat biaya medis ${ }^{[9]}$.

\section{DU $90 \%$}

Terdapat 7 jenis antibiotik yang dikonsumsi pasien bedah orthopedi pada tahun 2017 pada tabel 2, dengan 4 jenis antibiotik yang masuk kedalam segmen DU $90 \%$ penggunaan yang terbanyak berturut-turut dari yang terbesar adalah ceftriaxone, cefixime, doxycillin, dan amoxicillin. Banyaknya variasi jenis antibiotik yang digunakan ini dapat menjadi peluang untuk terjadi resistensi terhadap antibiotik yang digunakan. Berdasarkan penelitian ini, para dokter dibagian bedah orthopedi cenderung meresepkan antibiotik lebih banyak yang umumnya adalah golongan antibiotik dengan spektrum luas yaitu golongan sefalosporin (ceftriaxone) yang lebih efektif mengurangi kejadian SSI (Site Surgical Infections).

Tabel 4. Kuantitas penggunaan antibiotik berdasarkan DDD/100 patient-days.

\begin{tabular}{llllll}
\hline No & Jenis Antibiotik & $\sum$ Dosis $(\mathrm{g})$ & DDD & DDD/100 & \% DDD \\
\hline 1 & Ceftriaxone & 279 & 139,5 & 20,21 & 77 \\
2 & Cefixime & 13,2 & 33 & 4,78 & 18,21 \\
3 & Doxycillin & 0,2 & 2 & 0,28 & 1,1 \\
4 & Amoxicillin & 4,5 & 4,5 & 0,65 & 2,49 \\
5 & Cefadroxil & 2 & 1 & 0,14 & 0,55 \\
6 & Gentamicin & 0,16 & 0,67 & 0,09 & 0,37 \\
7 & Ceftazidime & 2 & 0,5 & 0,07 & 0,28 \\
\hline Total & & 301,06 & 181,17 & 26,22 & 100 \\
\hline
\end{tabular}

Tabel 5. Pola konsumsi antibiotik

\begin{tabular}{lllll}
\hline No & Jenis Antibiotik & DDD & $\%$ & Segmen DU \\
\hline 1 & Ceftriaxone & 20,21 & 77 & $90 \%$ \\
2 & Cefixime & 4,78 & 18,21 & \\
3 & Cefadroxil & 0,14 & 1,1 & \\
4 & Amoxicillin & 0,65 & 2,49 & $10 \%$ \\
\hline 5 & Doxycillin & 0,28 & 0,55 & \\
6 & Gentamicin & 0,09 & 0,37 & \\
7 & Ceftazidime & 0,07 & 0,28 & \\
\hline
\end{tabular}


Penelitian ini memiliki keterbatasan, dimana jumlah sampel tidak mencangkup seluruh pasien bedah orthopedi dan metode penelitian ini dilakukan secara retrospektif yang juga mempunyai kelemahan penulisan rekam medik yang tidak lengkap. Hasil penelitian ini dapat digunakan untuk dibandingkan penggunaan antibiotik dengan bangsal bedah lain ataupun rumah sakit lainnya dan dapat digunakan sebagai informasi dalam melakukan perencanaan pengadaan obat yang akan digunakan.

\section{KESIMPULAN}

Hasil penelitian ini menunjukkan sebaran karakteristik pasien bedah orthopedi berjenis kelamin laki-laki sebesar 54 pasien $(63,52 \%)$, usia 46-65 tahun sebesar 39 pasien $(41,18 \%)$, dan jenis pekerjaan swasta sebesar 34 pasien (40\%). Kuantitatas penggunaan antibiotik terbanyak pada pasien bedah orthopedi di RSUD Abdul Wahab Sjahranie Samarinda adalah ceftriaxone sebanyak 20,21 DDD/100 patient-days dan antibiotik yang masuk dalam segmen DU 90\% adalah ceftriaxone, cefixime, cefadroxil, dan amoxicillin.

\section{DAFTAR PUSTAKA}

[1] Badan Pusat Statistika Kalimantan Timur. 2016. Diaskes tanggal 23 maret $2018 . \quad$ dari https://kaltim.bps.go.id

[2] Chang Fangrong, Li Maosheng, $\mathrm{Xu}$ Pengpeng, Zhou Hanchu, Haque Md. Mazharul, and Huang Helai. 2016. Injury severity of motorcycle Riders involved In Traffic Crashes in Hunan, China: A mixed ordered logit Approach. International Journal of environmental research and public health. China.

[3] Fazriyah, Nurul. 2016. Evaluasi Penggunaan Antibiotik Profilaksis Pada Bedah Apendektomi Dengan Metode ATC/DDD Dan DU 90\% Di
Rumah Sakit Umum Daerah Cengkareng Periode JanuariDesember. UIN Syarif Hidayatullah . Jakarta

[4] Grace, Pierce A, Neil R. Borley. 2007. At a Glance Ilmu Bedah. edisi ketiga. Jakarta. Erlangga

[5] Hamdi, Sozen, Ibak gonen, Ayse sozen, Ali Kutlucan, Serdar Kalemci, and Murat Sahan. 2013. Application of ATC/DDD Methodology To Evaluate of Antibiotic Use Ina a General Hospitalin Turkey. Annals of Clinical Microbiology and Antimicrobials Suleyman Demirel University. Isparta. Turkey.

[6] Kemenkes RI. 2013. Riset Kesehatan Dasar. Badan Penelitian dan Pengembangan Kesehatan Kementrian Kesehatan RI. Jakarta

[7] Kigera JWM, and Turyakira C. 2012. Audit of Prophylactic Antibiotic Use Orthopaedic Surgery In Mulago Hospital.. The Annals of African Surgery. Volume 09. Makerere University. Kampala, Uganda.

[8] Mariana. Anni Tiurma dan Fatwa Sari Tetra Dewi. 2018. Cedera Akibat Kecelakaan Lalulintas Di Sleman : Data HDSS 2015 Dan 2016. BKM Journal of Community Medicine And Public Health. Volume 34 Nomor 6 Tahun 2018.

[9] Nisa Najwa Rokhmah, Retnosari Andrajati, Maksum Radji. 2017. Cross-Sectional Study of Surgical Prophylactic Antibiotic Administration In Marzoeki Mahdi Hospital, Bogor, Indonesia. Asian journal of pharmaceutical and clinical research. Volume 10, issue 11.2017

[10]Permatasari, Dwi. 2013. Kuantitas dan Kualitas Penggunaan Antibiotika pada Pasien Dewasa Fraktur Terbuka Tibia Di RSUP Fatmawati. Fakultas kedokteran dan Ilmu Kesehatan. Jakarta 
Studi Penggunaan Antibiotik berdasarkan ATC/DDD pada Pasien Bedah Orthopedi di RSUD Abdul Wahab Sjahranie Samarinda

[11] Suwandra, Reza, Rico Januar Sitorus, Hamzah Hasyim. 2011.

Analisis Kejadian Kecelakaan Lalu Lintas Di Kota Palembang Tahun 2008-2009. Jurnal Ilmu Kesehatan Masyarakat Volume 2 Nomor 02. 